
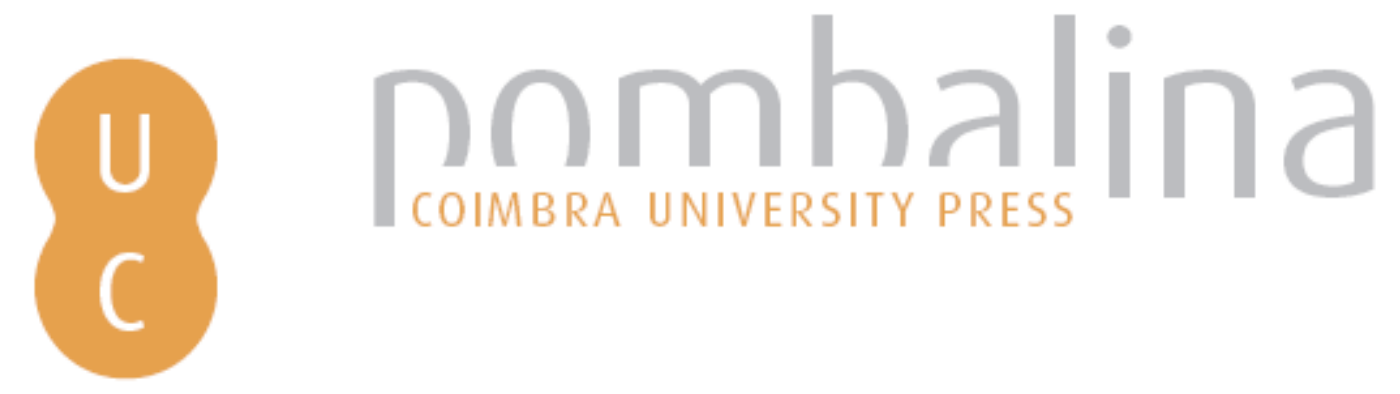

\title{
Towards an ultra-low-power low-cost wireless visual sensor node for fine-grain detection of forest fires
}

\author{
Autor(es): $\quad$ Fernández-Berni, J.; Carmona-Galán, R.; Leñero-Bardallo, Juan A.; \\ Kleihorst, R.; Rodríguez-Vázquez, Á.
}

Publicado por: Imprensa da Universidade de Coimbra

URL persistente:

URI:http://hdl.handle.net/10316.2/34180

DOI:

DOI:http://dx.doi.org/10.14195/978-989-26-0884-6_173

Accessed : $\quad$ 26-Apr-2023 13:20:05

A navegação consulta e descarregamento dos títulos inseridos nas Bibliotecas Digitais UC Digitalis, UC Pombalina e UC Impactum, pressupõem a aceitação plena e sem reservas dos Termos e Condições de Uso destas Bibliotecas Digitais, disponíveis em https://digitalis.uc.pt/pt-pt/termos.

Conforme exposto nos referidos Termos e Condições de Uso, o descarregamento de títulos de acesso restrito requer uma licença válida de autorização devendo o utilizador aceder ao(s) documento(s) a partir de um endereço de IP da instituição detentora da supramencionada licença.

Ao utilizador é apenas permitido o descarregamento para uso pessoal, pelo que o emprego do(s) título(s) descarregado(s) para outro fim, designadamente comercial, carece de autorização do respetivo autor ou editor da obra.

Na medida em que todas as obras da UC Digitalis se encontram protegidas pelo Código do Direito de Autor e Direitos Conexos e demais legislação aplicável, toda a cópia, parcial ou total, deste documento, nos casos em que é legalmente admitida, deverá conter ou fazer-se acompanhar por este aviso.

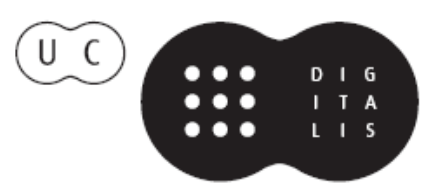




\section{ADVANCES IN}

Forest Fire

\section{RESEARCH}

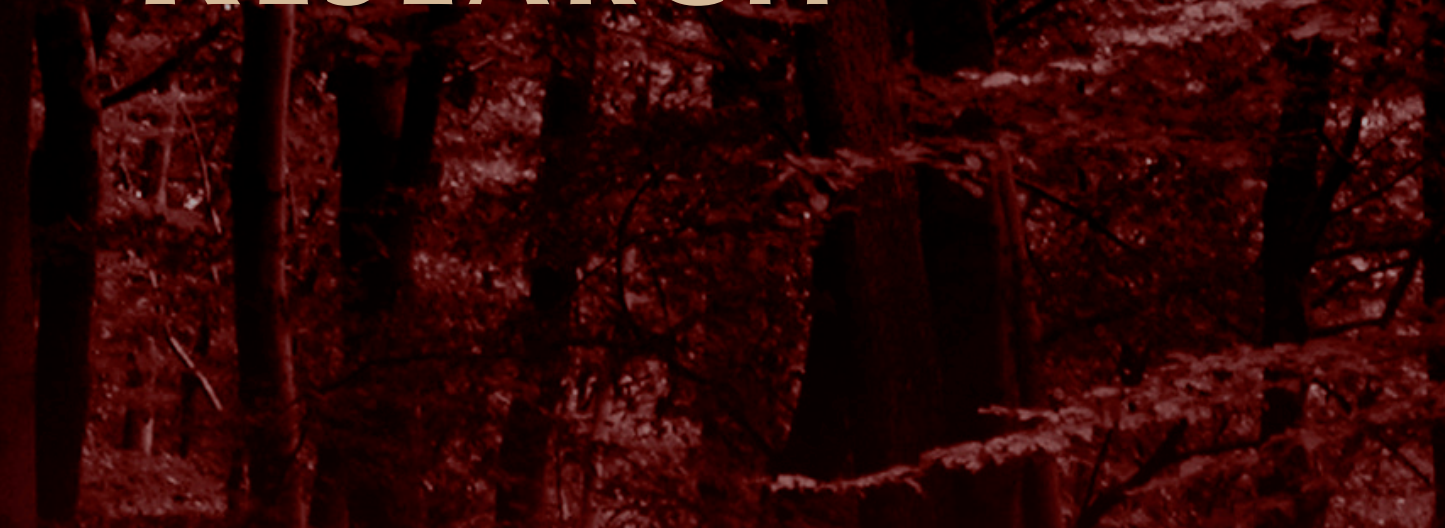

\section{DOMINGOS XAVIER VIEGAS}

\section{EDITOR}




\title{
Towards an ultra-low-power low-cost wireless visual sensor node for fine-grain detection of forest fires
}

\author{
J. Fernández-Berni ${ }^{\mathrm{a}}$, R. Carmona-Galán ${ }^{\mathrm{a}}$, Juan A. Leñero-Bardallo ${ }^{\mathrm{a}}$, R. Kleihorst ${ }^{\mathrm{b}}$, Á. Rodríguez- \\ Vázquez ${ }^{\mathrm{a}}$ \\ ${ }^{a}$ Institute of Microelectronics of Seville (CSIC - Universidad de Sevilla), Avda. Américo Vespucio \\ s/n Seville (Spain), berni@imse-cnm.csic.es \\ ${ }^{b}$ Ghent University/iMinds/TELIN-IPI. St-Pietersnieuwstraat 41 Ghent (Belgium), \\ rkleihor@telin.ugent.be
}

\begin{abstract}
Advances in electronics, sensor technologies, embedded hardware and software are boosting the application scenarios of wireless sensor networks. Specifically, the incorporation of visual capabilities into the nodes means a milestone, and a challenge, in terms of the amount of information sensed and processed by these networks. The scarcity of resources - power, processing and memory - imposes strong restrictions on the vision hardware and algorithms suitable for implementation at the nodes. Both, hardware and algorithms must be adapted to the particular characteristics of the targeted application. This permits to achieve the required performance at lower energy and computational cost. We have followed this approach when addressing the detection of forest fires by means of wireless visual sensor networks. From the development of a smoke detection algorithm down to the design of a low-power smart imager, every step along the way has been influenced by the objective of reducing power consumption and computational resources as much as possible. Of course, reliability and robustness against false alarms have also been crucial requirements demanded by this specific application. All in all, we summarize in this paper our experience in this topic. In addition to a prototype vision system based on a full-custom smart imager, we also report results from a vision system based on ultra-low-power low-cost commercial imagers with a resolution of $30 \times 30$ pixels. Even for this small number of pixels, we have been able to detect smoke at around 100 meters away without false alarms. For such tiny images, smoke is simply a moving grey stain within a blurry scene, but it features a particular spatio-temporal dynamics. As described in the manuscript, the key point to succeed with so low resolution thus falls on the adequate encoding of that dynamics at algorithm level.
\end{abstract}

Keywords: forest fires, surveillance systems, wireless sensor networks, automatic early detection, artificial vision, low-power sensors, vision algorithms.

\section{Introduction}

Wireless Sensor Networks (WSNs) (Akyildiz et al. 2002) constitute an enabling technology for the paradigm of pervasive computing (Weiser 1991). One of the most representative application frameworks of this paradigm is environmental monitoring. Typical scenarios are precision agriculture (McCulloch et al. 2008), forest canopy analysis (Tolle et al. 2005), volcanic studies (Werner-Allen et al. 2006), meteorological station networks (Barrenetxea et al. 2008) etc. In all these cases, the network nodes incorporate particular sensing capabilities according to the requirements of the application considered. These capabilities share a common feature: they provide scalar measurements, e.g. temperature, humidity or wind speed. Moreover, the data sampling rate is usually low or moderate at most, leading to a reduced amount of information to be handled locally by the nodes. These conditions significantly change when it comes to the in-node implementation of multimedia sensing (Akyildiz et al. 2007). Specifically, the implementation of vision hardware at WSN nodes is not a trivial issue at all since the visual stimulus implies to deal with a massive flow of multidimensional information. Taking into account the very strict power budgets allocated to the nodes, the mere capture and digitization of an image sequence could represent a significant percentage of their energy consumption. 
But the critical point arises just afterwards. On the one hand, the sequence could simply be transmitted for remote processing, affecting dramatically the scalability and bandwidth of the network. On the other hand, the node itself could deal with the image sequence by taking advantage of its processing capabilities. In this case, the nature of such processing is greatly influenced by the energy constraints, demanding new strategies which permit to reach the targeted result with the minimum possible power cost.

Most WSN applications take a new dimension when imaging is added to the catalogue of in-node sensing capabilities. A clear example is wildfire monitoring. Image processing permits not only to monitor a certain area from the perspective of environmental conditions (Hefeeda 2007, Aslan et al. 2012), but also to carry out visual inspection in order to perform early detection of smoke or flames (Fernández-Berni et al. 2012, Jakovcevic et al. 2013). At the moment, two fundamental intertwined challenges are hindering the commercial exploitation of vision-enabled WSNs performing fine-grain detection of forest fires: node cost and battery life. A scalable deployment of sensors across typical regions of interest for fine-grain detection, e.g. Wild-land Urban Interfaces (WUIs), demands a competitive cost per node, what in turn demands the use of standard technologies and reduced form factors. Maintenance also plays a key role in terms of system cost when hundreds of vision-enabled nodes are to be deployed. Frequent change of batteries directly impacts the commercial viability of the network. Rechargeable batteries making use of solar panels or other energy-scavenging devices could be a solution, but they significantly increase the node form factor and the cost. They also strongly influence the locations of the sensors, which must be adequate for the particular physical process collecting energy. These considerations again point to ultra-low power consumption as the primary requirement of vision-enabled WSNs, a fact that is emphasized for the specific application of forest fire detection.

All in all, we summarize in this paper our contribution to the power-efficient implementation of vision hardware on wireless sensor network nodes targeting early detection of forest fires. This contribution is the result of long-term research. The tasks carried out range from devising a robust vision algorithm for smoke detection to the design and physical implementation of a power-efficient smart imager tailored to the characteristics of such an algorithm. By integrating this smart imager with a commercial wireless platform, we endowed the resulting system with vision capabilities and radio communication. Numerous tests were arranged in different natural scenarios in order to progressively tune all the parameters involved in the autonomous operation of this prototype node. We have also studied the performance of another platform based on commercial components, the so-called Silicam IGO (Silicam 2014). This smart camera includes two low-cost image sensors with a resolution of only $30 \times 30$ pixels. Reliable smoke detection is still possible in real scenarios even for such a small amount of visual information. Indeed, the low resolution itself can be a helpful mechanism to filter out spurious data. Experimental results are presented for both systems.

\section{Methodology}

The methodology followed to address early forest fire detection by vision-enabled WSNs comprises: i) the development of a reliable vision algorithm for smoke detection suitable for embedded systems, that is, featuring low computational load and undemanding memory requirements; ii) the recording of meaningful footage for algorithm parameter tuning and off-line tests; iii) the implementation of the algorithm on a commercial system for preliminary field tests; iv) the design and implementation of a vision-enabled WSN node based on a full-custom smart imager; v) field tests in real scenarios; and vi) exploration of a new low-cost platform aiming at increasing power efficiency while preserving system reliability and robustness against false alarms. 


\subsection{Vision algorithm for smoke detection}

The general conditions in which the visual inspection of a vegetation area will take place for the targeted system must be specified before addressing the design of a vision algorithm for smoke detection. The requirements for camera systems surveying extensive areas from very tall towers - the most usual scenario for automatic detection of forest fires - are very different to those of visionenabled nodes in a WSN. In our case, we are pursuing an arrangement of watching devices like the one depicted in Figure 1. This arrangement presents several advantages when compared to current automatic ground systems (Fernández-Berni et al. 2008). Basically, the objective is to exploit the lowcost and low-power features of the nodes in order to increase the surveillance grain, what in principle should lead to a faster, more reliable and more robust detection. We therefore devised a vision algorithm assuming that each vision sensor surveys a small vegetation area located around it within a limited range (typically $1 \mathrm{~km}$ ).

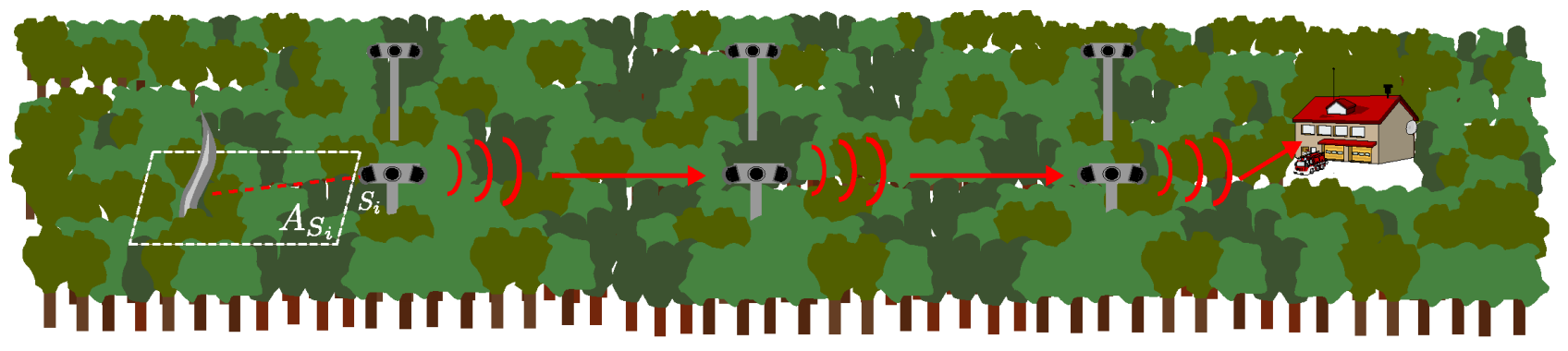

Figure 1. Proposed arrangement for visual detection of smoke.

Most of the details of the algorithm were described in (Fernández-Berni et al. 2012). However, we have introduced some minor modifications that were applied for the tests realized after that publication. They have resulted in higher robustness against false alarms. The modifications consisted in: i) setting a longer time interval for the maximum detection period and for the confirmation phase, now encoded by $T_{D_{M A X}}=60 \mathrm{~s}$ and $T_{C}=12 \mathrm{~s}$; ii) making the transition between the detection phase and the confirmation phase more flexible by not updating the background model as soon as the number of candidate bins goes below the corresponding threshold, as was the case for the previous version. The new flowchart of the algorithm is represented in Figure 2. These modifications are really interrelated since it is the larger values of $T_{D_{M A X}}$ and $T_{C}$ what allows for accommodating a wider spectrum of smoke dynamics without triggering false alarms.

\subsection{Parameter tuning and off-line tests}

The discriminative power of the proposed algorithm is fundamentally supported by an adequate setting of the thresholds associated to its parameters. Such setting was performed by a thorough analysis of different sequences recorded in a natural environment, using commercial pyrotechnic material as smoke generator. We also recorded additional footage useful as a testbench and took a number of photographs in the variety of real scenarios we visited during all the field tests arranged the last few years. Most of this material is available for download at http://www.imse-cnm.csic.es/vmote (accessed 21 May 2014). 


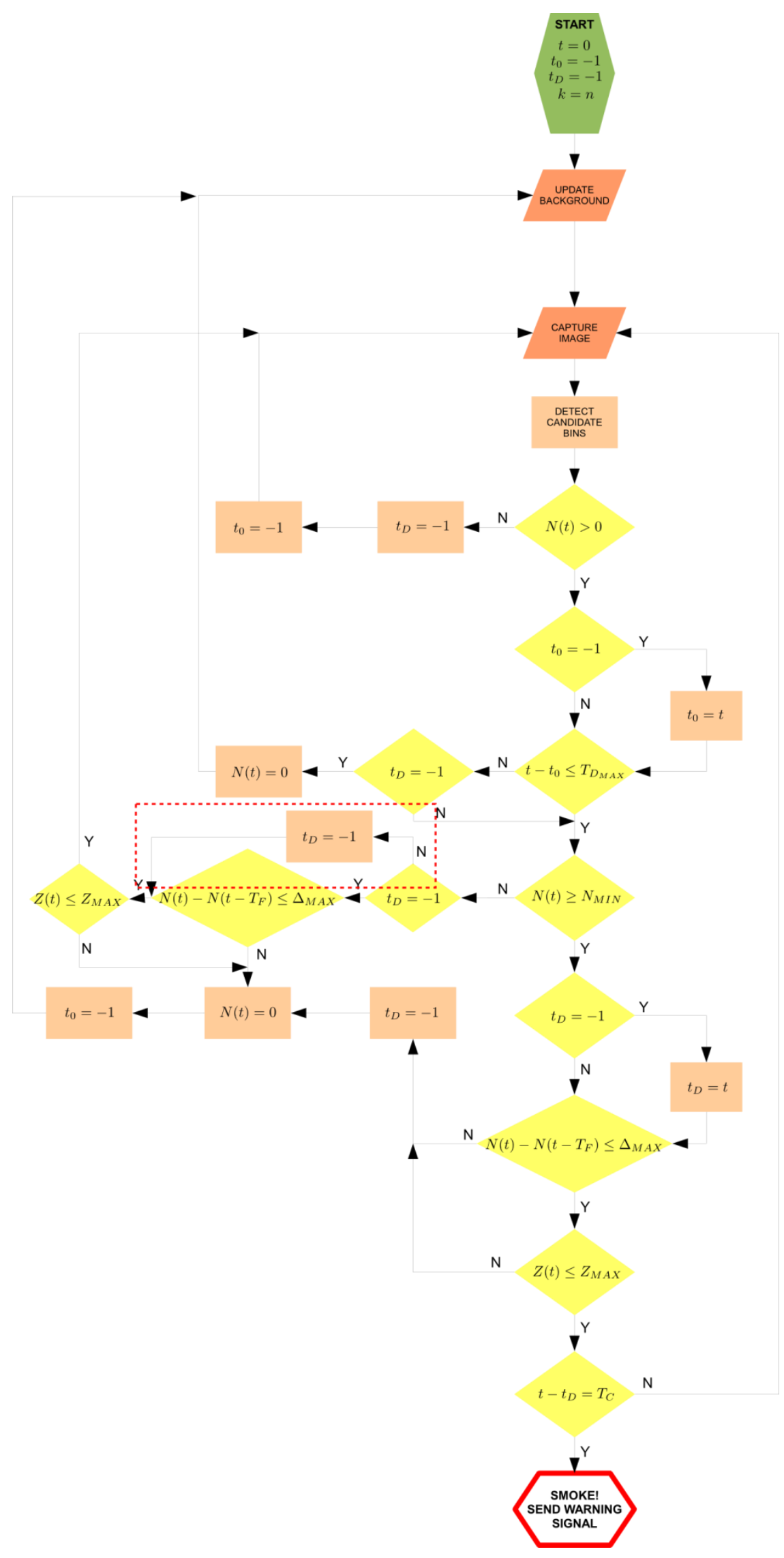

Figure 2. Flowchart of the algorithm. The modification related to the transition between the detection phase and the confirmation phase is highlighted by a red dashed rectangle. 


\subsection{Field tests with a commercial system}

Once the algorithm was tuned for smoke detection, we programmed it into the EyeRIS v1.2, a commercial autonomous vision system built by AnaFocus Ltd (Seville, Spain, http://www.anafocus.com, accessed 22 May 2014). After a setup stage in the laboratory, two controlled burns of forest debris were surveyed by this system in order to test the algorithm in a real scenario. This test was also useful to learn and cope with typical operational problems of field experiments, permitting a better arrangement in following trials. All the details about these burns can be found in (Fernández-Berni et al. 2012). As a summary, smoke was detected without false alarms in both cases. In the first, the alarm was triggered at $2 \mathrm{~min} 50$ s from ignition, whereas in the second, the alarm was delivered after $57 \mathrm{~s}$. The most remarkable aspect about the results was the algorithm's ability to filter motion other than smoke.

\subsection{Design and implementation of a vision-enabled WSN node}

The successful tests with the EyeRIS system demonstrated the viability of reliable forest fire smoke detection with low-power low-resolution autonomous vision systems in a scenario like that of Figure 1. But we wanted to go further concerning power efficiency and also to incorporate wireless communication to the sensor node. Based on our expertise on microelectronics, and specifically on vision sensor chips, we addressed the design and implementation of an ultra-low-power smart imager embedding different processing capabilities (Fernández-Berni et al. 2011-1). This chip met several academic purposes, one of which was to play a key role in the prototype vision-enabled WSN node we built, the so-called Wi-FLIP system (Fernández-Berni et al. 2011-2), shown in Figure 3. This system resulted from the integration of our smart imager and Imote2, a commercial WSN platform from MEMSIC Corporation (Andover, MA, www.memsic.com, accessed 22 May 2014). This platform is built around a microprocessor that can operate in a low-voltage low-frequency mode, hence allowing low-power operation. A ZigBee-compliant radio is also integrated into the Imote 2 system.
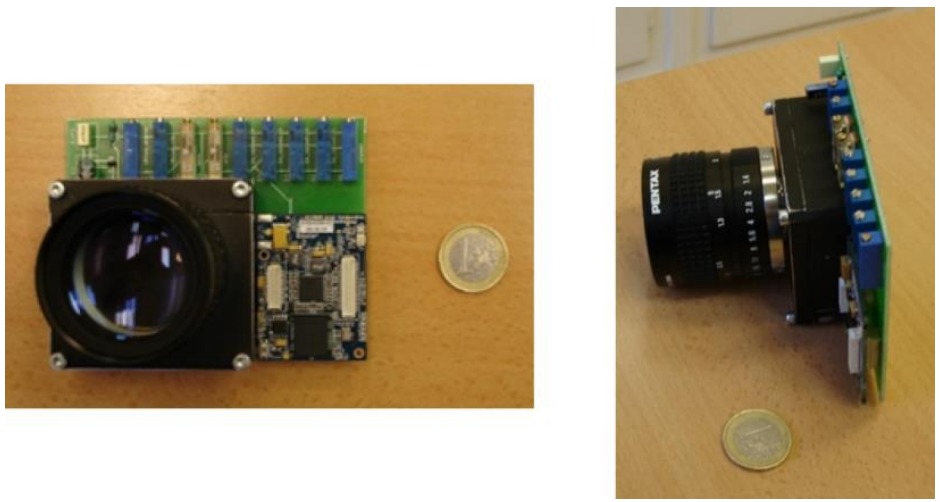

Figure 3. Wi-FLIP, a vision-enabled WSN node based on a focal-plane low-power image processor.

\subsection{Field tests in real scenarios}

As for the EyeRIS system, we also arranged for some preliminary tests with the Wi-FLIP system after the corresponding setup in the laboratory. Such tests took place in the same public park where we recorded the smoke sequences enabling the algorithm parameter setting. Once the whole system was tuned during these preliminary trials, additional tests involving controlled burns of vegetation areas were carried out in collaboration with the Andalusian Forest Fire Suppression and Prevention Service (INFOCA). These tests, whose results will be described in the next section, generated alarm signals as an outcome. The alarms were wirelessly sent to a base station located within a range of $30 \mathrm{~m}$. Also images were sparsely broadcast from Wi-FLIP since an alarm signal was triggered. This would permit 
further visual checking from personnel supervising the network. Some of the scenarios where the field tests took place are depicted in Figure 4.
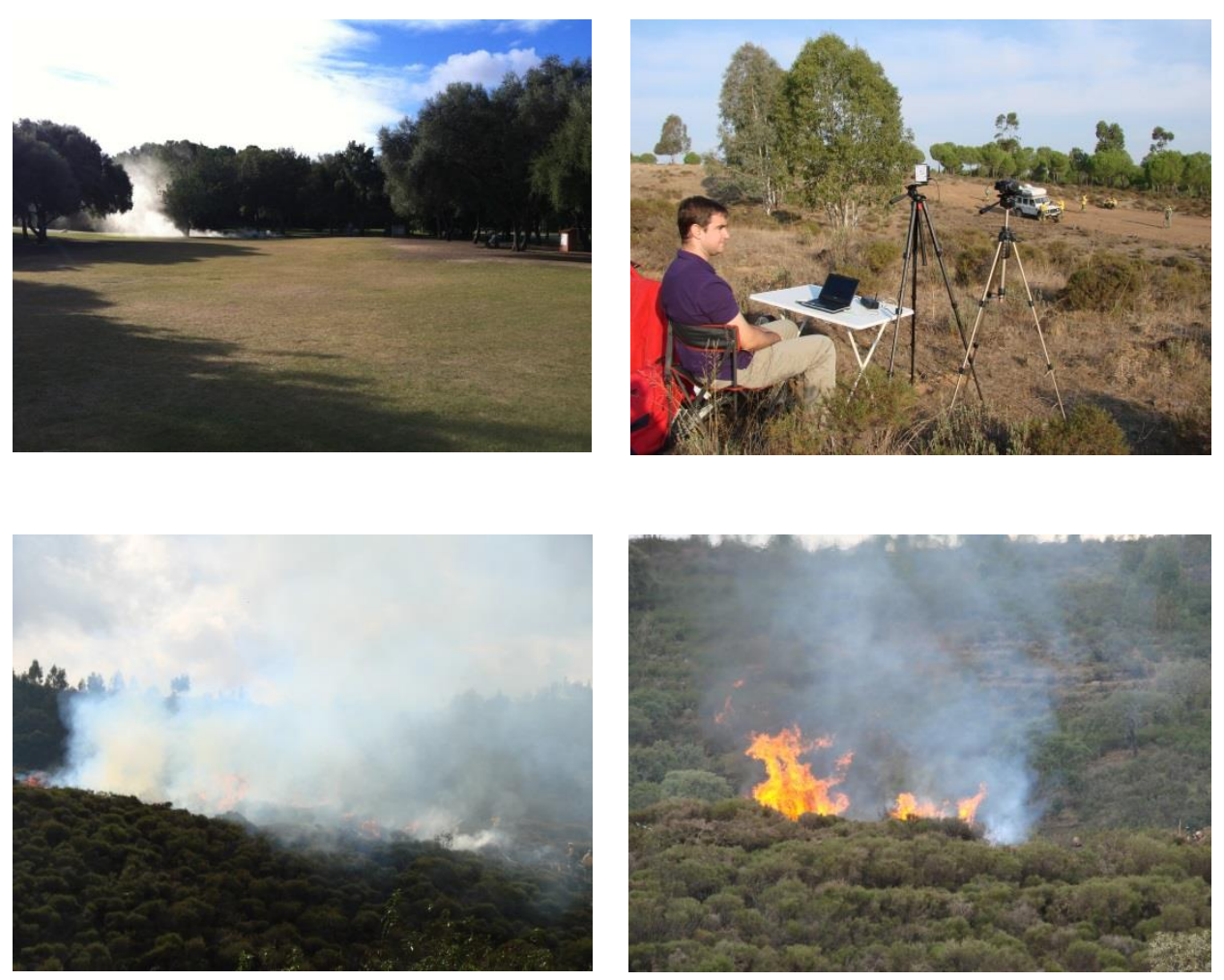

Figure 4. Some of the scenarios where our field tests took place.

\subsection{Exploration of a new ultra-low-power low-cost vision platform}

As stated in Section 1, node cost and battery life are currently hindering the commercial exploitation of vision-enabled WSNs for fine-grain detection of forest fires. The performance of the Wi-FLIP system has been remarkable as a first prototype, providing autonomous operation for $\sim 10 \mathrm{~h}$ powered by small commercial batteries. However, further steps must be given to reach much better performance figures at lower cost. In this context, we have had the possibility of running the algorithm on the images provided by the platform Silicam IGO (Silicam 2014). This is the first version of a commercial embedded vision system including, among other components, two grayscale $30 \times 30-p x$ image sensors and a radio module with 64 channels whose cost does not go beyond a few dollars. Indeed, the imagers are high-performance optical mouse sensors. A really competitive network node in economic terms can be built up from these extremely cheap modules. But the first step is to evaluate how the algorithm performs when being fed by so coarse images. This is what we have done during the realization of new field tests by making use of the Silicam IGO platform. A couple of snapshots of this system are shown in Figure 5. 


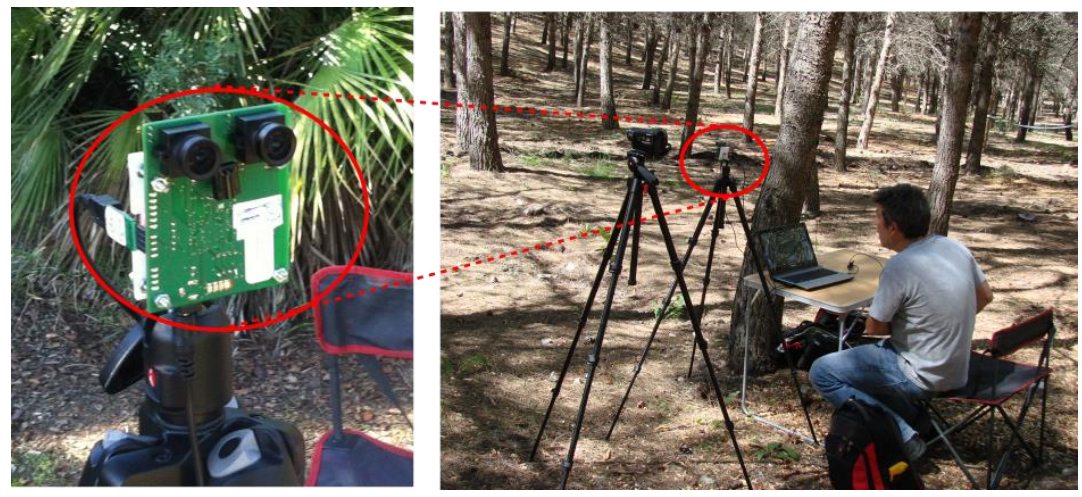

Figure 5. Silicam IGO platform capturing images for on-site smoke detection.

\section{Results}

This section reports the experimental results achieved from both the Wi-FLIP and the Silicam systems. Concerning Wi-FLIP, some results were already described in (Fernández-Berni et al. 2012) but we are gathering here those results together with the new ones obtained after that publication. A complete perspective of the Wi-FLIP performance is thus provided.

\subsection{Wi-FLIP}

As mentioned in Section 2.5, the operation of Wi-FLIP was first tuned in the same public park where the video sequences for the algorithm settings were recorded. The setting up of these tests was complicated due to strong gusts of wind. Nevertheless, no false alarm was triggered during eight sequences of smoke generation and detection was successful in five of them. Smoke was not successfully detected in the others because, owing to the wind, the pyrotechnic material burnt out before it had entered the field of view of Wi-FLIP sufficiently to be registered.

The next test consisted in surveying the prescribed burning of a $95 \times 20-\mathrm{m}^{2}$ area of vegetation in a public forest in collaboration with INFOCA. This area was mechanically divided into three zones of similar sizes according to the density of vegetation. Wi-FLIP was placed $\sim 80 \mathrm{~m}$ away and monitored all the activity occurring in it for over $2 \mathrm{~h}$. The first zone presented very sparse vegetation, generating very thin smoke that was not detected by Wi-FLIP. However, successful detection took place for the second and third zones. A first alarm was triggered $5 \mathrm{~min} 28 \mathrm{~s}$ after ignition for the second zone whereas it took $3 \mathrm{~min} 29 \mathrm{~s}$ to trigger an alarm for the third zone. No false positives were triggered either before or after the prescribed burn, despite the fact that many people and vehicles were moving around.

Finally, a new test similar to the just described was arranged in a different location of the same public forest. In this case, the operation conditions were harder. To start with, the wireless vision system was placed $\sim 200 \mathrm{~m}$ away from the prescribed burning. Fast cloud motion was constantly changing the illumination conditions. The motion of people and vehicles was even more intense than for the previous test. The surveillance period was $\sim 2 \mathrm{~h}$. Two false alarms were triggered during this interval. The first one was caused by clouds that entered the field of view of Wi-FLIP rapidly. The second one was generated by a sudden change of illumination. Despite these false alarms, the algorithm was capable of filtering out most of the constant activity taking place in the scene other than smoke. Detection was successful for the three zones of the prescribed area progressively burnt. The detection time from ignition was always below $8 \mathrm{~min}$ : $3 \mathrm{~min} 40 \mathrm{~s}$ for the first zone, $5 \mathrm{~min} 4 \mathrm{~s}$ for the second one and $7 \mathrm{~min} 26 \mathrm{~s}$ for the last zone. The background model just before starting to survey the third controlled burn along with the foreground segmentation of smoke at the detection instant and the first image sent via radio are depicted in Figure 6. It can be seen that some false candidate bins were segmented at the 
detection instant. However, it did not prevent the fire from being detected. We have summarized the experimental results achieved with Wi-FLIP in Table I.

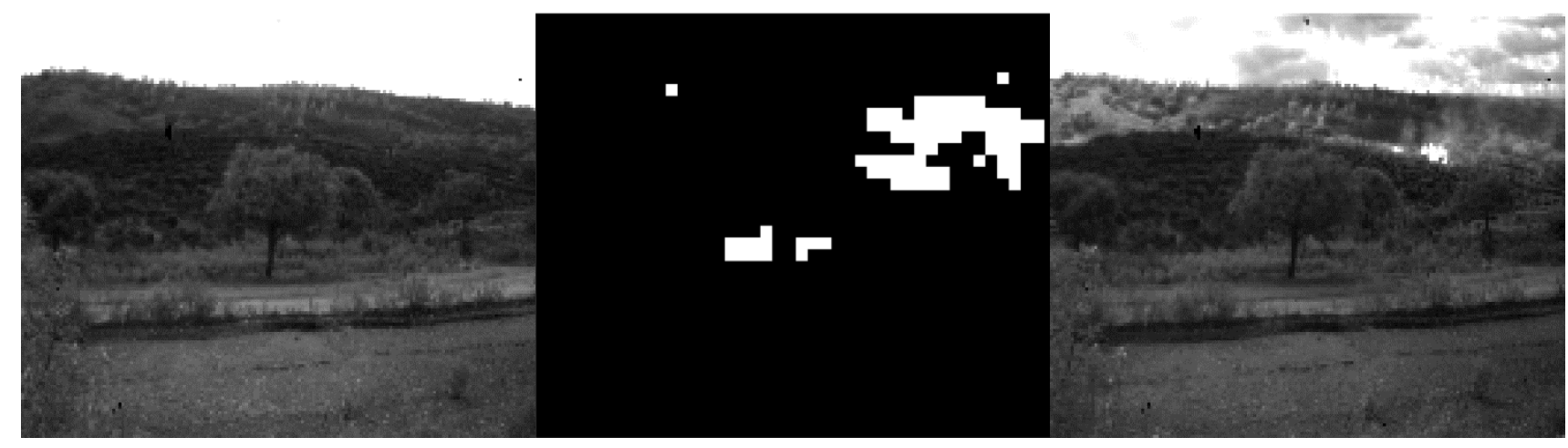

Figure 6. Initial background (left), foreground segmentation (center) and image sent via radio by Wi-FLIP (right) during one of the field tests carried out.

Table I - Summary of the experimental results achieved with Wi-FLIP.

\begin{tabular}{lcccccc} 
Test\#-Location & $\begin{array}{c}\text { Smoke } \\
\text { source }\end{array}$ & $\begin{array}{c}\text { Surveillance } \\
\text { period }\end{array}$ & $\begin{array}{c}\text { True } \\
\text { positives }\end{array}$ & $\begin{array}{c}\text { False } \\
\text { positives }\end{array}$ & $\begin{array}{c}\text { False } \\
\text { negatives }\end{array}$ & $\begin{array}{c}\text { Detection time } \\
\text { (distance) }\end{array}$ \\
\hline \#1-Public park & Pyrotechnic & $\sim 20 \mathrm{~m}$ & 5 & 0 & 3 & $\begin{array}{c}43 \mathrm{~s} \mathrm{max} \\
(\sim 100 \mathrm{~m})\end{array}$ \\
\hline \#2-Public forest & $\begin{array}{c}\text { Controlled } \\
\text { burns }\end{array}$ & $\sim 2 \mathrm{~h} \mathrm{30m}$ & 2 & 0 & 1 & $\begin{array}{c}5 \mathrm{~m} 28 \mathrm{~s} \max \\
(\sim 80 \mathrm{~m})\end{array}$ \\
\hline \#3-Public forest & $\begin{array}{c}\text { Controlled } \\
\text { burns }\end{array}$ & $\sim 2 \mathrm{~h}$ & 3 & 2 & 0 & $\begin{array}{c}\mathrm{m} 26 \mathrm{~s} \max \\
(\sim 200 \mathrm{~m})\end{array}$
\end{tabular}

\subsection{Silicam}

We also arranged for a first set of field trials with Silicam in a public park. Pyrotechnic material was again used as smoke source. It was burnt out within distances between $\sim 50 \mathrm{~m}$ and $\sim 100 \mathrm{~m}$ with respect to the vision system. Only one of the imagers of Silicam was used. No false alarm was triggered during the seven smoke sequences analysed at four different locations. There was only one false negative due to lack of contrast of the generated smoke against the background. Successful detection was achieved for the other six sequences. The background model at the detection instant along with the captured image and foreground segmentation at that same moment for one of these sequences are depicted in Figure 7.

A controlled burn in a public forest could be surveyed with Silicam too. However, the arrangements for this test were far from ideal. First of all, the vegetation to be burnt was sparse and relatively damp, generating thin smoke. The characteristics of the surroundings were not suitable either for adequate surveillance: tall trees prevent the thin smoke arising from the burn from being detected from higher locations. The trees also caused high illumination contrast in the visual scene, making the detection more challenging. We had to place Silicam very close to the ignition points, what at least permitted to confirm once again the robustness of the algorithm against false alarms: there was only one throughout the over $2 \mathrm{~h}$ of visual inspection. Detection was successful in three of the sequences analysed. Concerning false negatives, we consider that the smoke was thick enough to have being detected in other three sequences. One of the successful detections is shown in Figure 8. A couple of photographs taken during the realization of this test are included in Figure 9. The results achieved with Silicam are summarized in Table II. 

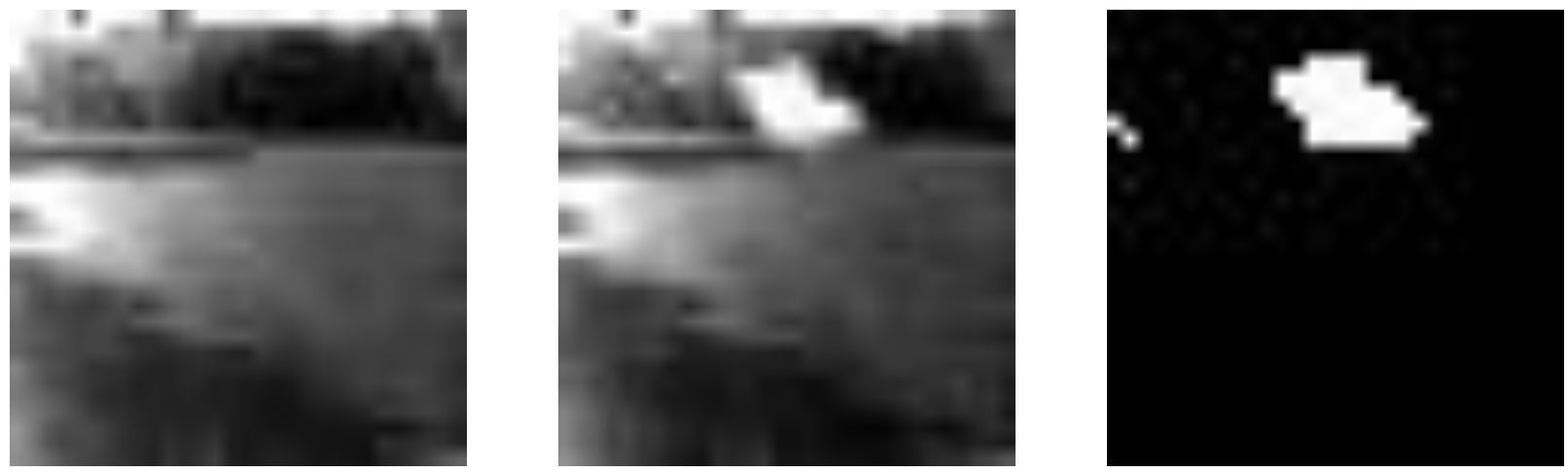

Figure 7. Background model (left), captured image (center) and foreground segmentation (right) just at the detection instant of smoke from pyrotechnic material with Silicam.
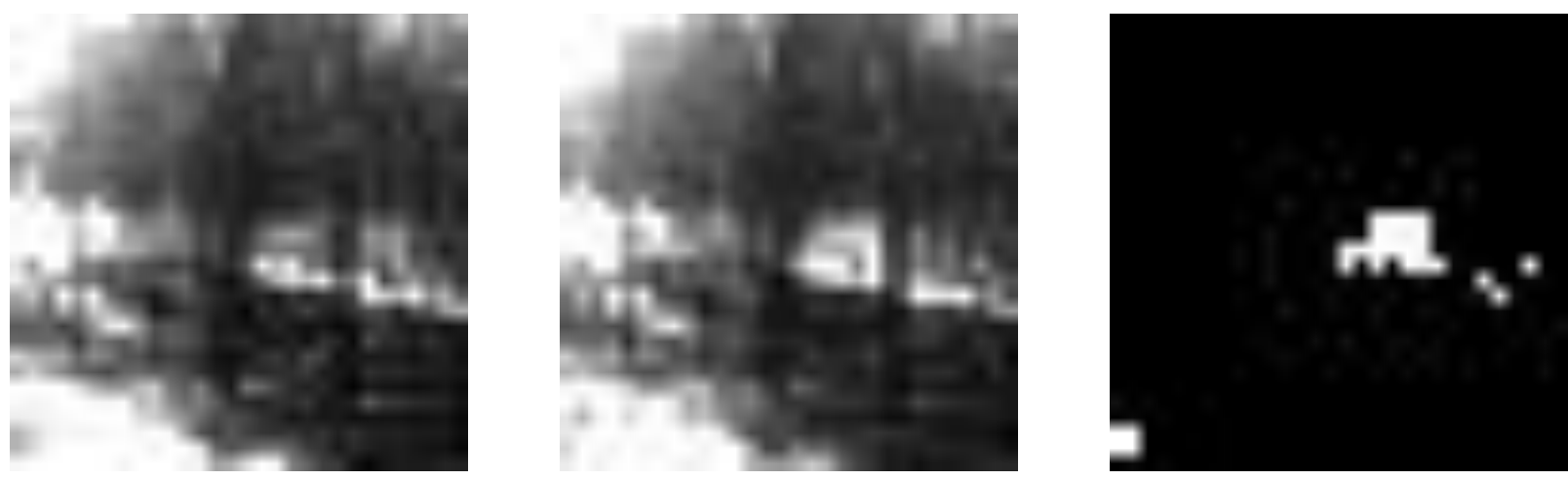

Figure 8. Background model (left), captured image (center) and foreground segmentation (right) just at the detection instant of smoke from controlled burn with Silicam.
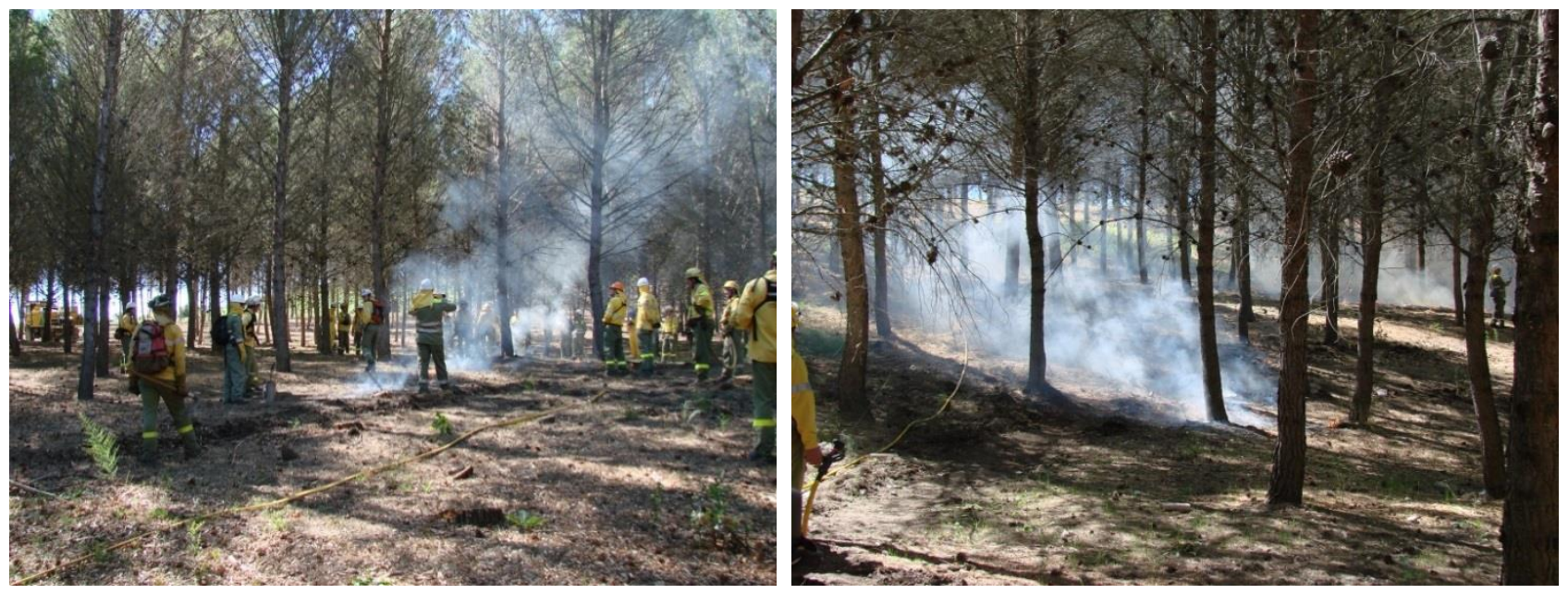

Figure 9. Snapshots taken during the controlled burn surveyed by Silicam. 
Table II - Summary of the experimental results achieved with Silicam.

\begin{tabular}{ccccccc} 
Test\#-Location & $\begin{array}{c}\text { Smoke } \\
\text { source }\end{array}$ & $\begin{array}{c}\text { Surveillance } \\
\text { period }\end{array}$ & $\begin{array}{c}\text { True } \\
\text { positives }\end{array}$ & $\begin{array}{c}\text { False } \\
\text { positives }\end{array}$ & $\begin{array}{c}\text { False } \\
\text { negatives }\end{array}$ & $\begin{array}{c}\text { Detection time } \\
\text { (distance) }\end{array}$ \\
\hline \#1-Public park & Pyrotechnic & $\sim 45 \mathrm{~m}$ & 6 & 0 & 1 & $\begin{array}{c}51 \mathrm{~s} \mathrm{max} \\
(\sim 100 \mathrm{~m})\end{array}$ \\
\hline \#2-Public forest & $\begin{array}{c}\text { Controlled } \\
\text { burns }\end{array}$ & $\sim 2 \mathrm{~h} \mathrm{15m}$ & 3 & 1 & 3 & $\begin{array}{c}4 \mathrm{~m} 7 \mathrm{~s} \mathrm{max} \\
(\sim 30 \mathrm{~m})\end{array}$
\end{tabular}

\section{Conclusions}

Fine-grain detection of forest fires is technologically possible nowadays. State-of-the-art visionenabled WSN nodes can be deployed throughout a region of interest to locally survey small vegetation areas and wirelessly send alarm messages by multi-hopping. However, operational costs still seem to be very high for a dense deployment. Node cost and battery life demand new strategies that permit to reduce the former while increasing the latter. In this paper, we have described our contribution to achieve such objective. Tight integration of the different system components arises as a major requirement. Among these components, the vision algorithm for detection stands out as the primary demander of computational power and hence of power consumption. The algorithm proposed in this manuscript features low computational load and can also cope with very low resolution images. The results from the numerous field tests presented suggest pushing in this direction by further algorithm tuning. To this end, the feedback provided by real deployments in different locations and circumstances is mandatory, according to our experience. Ultra-low power consumption and miniaturization should ultimately lead to the seamless integration of vision within the catalogue of sensing capabilities available for WSNs.

\section{Acknowledgments}

The authors express their deep gratitude to Mr Salvador Benítez Moscoso, Mr Manuel Larios de la Carrera and Mr Francisco Senra Rivero of INFOCA for arranging the burns. This work has been funded by the Spanish Government through projects TEC2012-38921-C02 MINECO (European Region Development Fund, ERDF/FEDER), IPT-2011-1625-430000 MINECO and IPC-20111009 CDTI (ERDF/FEDER), by Junta de Andalucía through project TIC 2338-2013 CEICE, by the Office of Naval Research (USA) through grant N000141410355 and by Ghent University through its BOF program for visiting foreign researchers.

\section{References}

Akyildiz IF, Su W, Sankarasubramaniam Y, Cayirci E (2002) A survey on sensor networks. IEEE Communications Magazine 40(8), 102-114.

Akyildiz IF, Melodia T, Chowdhury KR (2007) A survey on wireless multimedia sensor networks. Computer Networks 51(4), 921-960.

Aslan YE, Korpeoglu I, Ulusoy O (2012) A framework for use of wireless sensor networks in forest fire detection and monitoring. Computers, Environment and Urban Systems 36(6), 614-625.

Barrenetxea G, Ingelrest F, Schaefer G, Vetterli M (2008). The hitchhiker's guide to successful wireless sensor network deployments. In 'Proc. of 6th Int. Conf. on Embedded Network Sensor Systems (SenSys)', 43-56.

Fernández-Berni J, Carmona-Galán R, Carranza-González L, (2008) A vision-based monitoring system for very early automatic detection of forest fires. In 'Proc. of I Int. Conf. on Modelling, Monitoring and Management of Forest Fires', 161-170. 
Fernández-Berni J, Carmona-Galán R, Carranza-González L, (2011-1) FLIP-Q: A QCIF resolution focal-plane array for low-power image processing. IEEE Journal of Solid-State Circuits 46(3), 669680.

Fernández-Berni J, Carmona-Galán R, Liñán-Cembrano G, Zarándy Á, Rodríguez-Vázquez Á, (20112) Wi-FLIP: A wireless smart camera based on a focal-plane low-power image processor. In 'Proc. of IEEE/ACM Int. Conf. on Distributed Smart Cameras (ICDSC)'.

Fernández-Berni J, Carmona-Galán R, Martínez-Carmona JF, Rodríguez-Vázquez A, (2012) Early forest fire detection by vision-enabled wireless sensor networks. International Journal of Wildland Fire 21, 938-949.

Hefeeda M, (2007). Forest fire modeling and early detection using wireless sensor networks. Tech. rept. School of Computing Science, Simon Fraser University.

Jakovcevic T, Stipanicev D, Krstinic D, (2013) Visual spatial-context based wildfire smoke sensor. Machine Vision and Applications 24(4), 707-719.

McCulloch J, McCarthy P, Guru SM, Peng W, Hugo D, Terhorst A, (2008) Wireless sensor network deployment for water use efficiency in irrigation. In 'Proc. of Workshop on Real-World Wireless Sensor Networks (REALWSN)', 46-50.

Silicam (2014). http://silicam.org/welcome/ [Online; accessed 04-May-2014].

Tolle G, Polastre J, Szewczyk R, Culler D, Turner N, Tu K, Burgess S, Dawson T, Buonadonna P, Gay D, Hong W, (2005). A macroscope in the redwoods. In 'Proc. of 3rd Int. Conf. on Embedded Networked Sensor Systems (SenSys)', 51-63.

Weiser M, (1991) The Computer for the 21th Century. Scientific American 265(3), 94-104.

Werner-Allen G, Lorincz K, Ruiz M, Marcillo O, Johnson J, Lees J, Welsh M (2006). Deploying a wireless sensor network on an active volcano. IEEE Internet Computing 10(2), 18-25. 